\title{
Otoritas Keagamaan Baru: Habituasi dan Arena Dakwah Era Digital
}

\author{
1* Didid Haryadi \\ ${ }^{1}$ Jurusan Sosiologi, Universitas Nasional, Indonesia
}

\begin{abstract}
The presence of the hijrah community in Indonesia directly resulted in the emergence of a new religious authority. Social media is a key factor in the massive campaign and regeneration carried out by the hijrah community. 'Terang Jakarta' and 'Shift Bandung' are two hijrah communities that have a very large number of congregations, especially on social media. This research attempts to answer the role of social media in shaping new patterns of new religious authority and to describe its relationship with traditional religious authority. Using a qualitative approach, this research finds that the formation of new religious authorities is more dominated by the prseference for preaching through social media, both by public figures and new religious teachers at the local level. These new religious authorities were actively involved in the hijrah community which they directly cultivated. Traditional religious authorities such as Nahdlatul Ulama (NU) and Muhammadiyah need to synergize programs with hijrah groups, especially in dakwah activities and religious moderation. This research considers that the Islamic Progressive group is an alternative movement capable of providing advocacy to all groups in Indonesia.
\end{abstract}

Keywords: New Religious Authority, Progressif Islam, 'Terang Jakarta', 'Shift Bandung'

\section{Latar belakang}

Komunitas 'Terang Jakarta' dan 'Shift Bandung' adalah representasi kelompok-kelompok hijrah yang ada di Indonesia. Hal ini berdasarkan besarnya pengaruh yang telah diberikan oleh dua komunitas ini kepada para jamaahnya. Selain itu, secara geografis Terang Jakarta dan Shift Bandung lahir di tengah kosmopolitnya kota dengan balutan modernisasi dan globalisasi yang mengiringi ritus sosial, politik, ekonomi, dan budaya anak-anak muda.

Fenomena hijrah di Indonesia sebenarnya telah muncul pada beberapa dekade sebelumnya. Hanya saja ada pergeseran terhadap kontekstual pemaknaan dan bentuk-bentuk persuasif yang menyentuh secara langsung baik dimensi sosial, ekonomi, budaya, maupun teknologi. Wakyudi Akmaliah, peneliti Pusat Penelitian Kemasyarakatan dan Kebudayaan Lembaga Ilmu Pengetahuan Indonesia, menjelaskan bahwa fenomena hijrah yang booming saat ini pernah terjadi di tahun 1970-an. Hanya saja terminologi yang digunakan pada medio itu adalah "Taubat" ketimbang diksi "Hijrah". "Meskipun tidak menggunakan kata hijrah, kebangkitan kelas menengah baru Muslim sudah terjadi sejak pertengahan decade 1970-an, seiring dengan adanya akses pendidikan modern bagi para santri awal tahun 1950-an. Pada tahun 1970-an, mereka yang mengenyam pendidikan modern menuasi hasilnya, di mana mereka memasuki dunia kerja dan bisnis 
serta mengalami kesuksesan". 1 Sementara itu, penegasan hal serupa dinyatakan oleh Muhammad As'ad di dalam artikel yang ditulis oleh Azhar Irfansyah, 'Ketika Hijrah Bukan Sekadar Perbaikan diri, tapi juga Aksi Kolektif, bahwa, 'makna 'Hijrah' digeser oleh Gerakan Hijrah dari makna teologis ke makna kultural". ${ }^{2}$

\section{Dengan menggunakan} pendekatan kualitatif, tulisan ini mengambil studi kasus pada komunitas 'Terang Jakarta' dan 'Shift Bandung'. Pengumpulan data dilakukan dengan observasi, wawancara terbuka yang mendalam dengan Dimas Adista ('Terang Jakarta') dan Wildan ('Shift Bandung'). Informan utama dalam riset ini memiliki pengetahuan yang komprehensif tentang sejarah awal munculnya komunitas yang mereka ikuti dan dinamika sosial kultural yang ada di dalamnya. Kriteria tersebut menjadi basis dalam proses pengumpulan data untuk selanjutnya dieksplorasi dengan konsep-konsep yang telah ditentukan.

Komunitas 'Terang Jakarta' dan 'Shift Bandung' merupakan representasi munculnya gerakan hijrah khususnya di kota-kota besar, seperti Jakarta dan Bandung. Dalam perkembangannya, gerakan hijrah menghadapi respon yang sangat dinamis dari publik. Misalnya, kehadiran gerakan hijrah dianggap menggeser eksistensi otoritas keagamaan tradisional di Indonesia yang selama ini telah memperoleh pengakuan baik oleh pemerintah maupun masyarakat, seperti Nahdlatul Ulama (NU) dan Muhammadiyah.

\footnotetext{
1 Arus Balik Hijrah (detik.com) https://tirto.id/ketika-hijrah-bukan-sekadar-
} perbaikan-diri-tapi-juga-aksi-kolektif-fZPP
Mayoritas anggota komunitas hijrah tidak memiliki latar belakang keilmuan agama yang berbasis pendidikan keagamaan di pesantren. Trajektori sosial kultural sebagai muslim perkotaan kelas menengah adalah karakteristik umum yang melekat pada mereka. Sumber pengetahuan keagamaannya diperoleh dari internet khusunya media sosial yang secara langsung memunculkan stigma pembelajaran Islam yang instan. Najib Kailani menyatakan bahwa fenomena hijrah yang menyebarkan dakwah Islami yang dikemas secara populer sebagai "Islam yang ready to use". "Gelombang hijrah meningkat karena komodifikasi wacana keislaman kencang. Para pemuda butuh sesuatu yang instan, dekat dengan mereka, tidak rumit, dan tak memunculkan kebimbangan". 3

Tulisan ini berusaha memberikan eksplanasi tentang dua hal; Pertama, bagaimana peran media sosial terhadap pembentukan pola otoritas keagamaan yang baru? Kedua, bagaimana hubungan antara otoritas keagamaan tradisional terhadap munculnya otoritas keagamaan yang baru?

\subsection{Otoritas Keagamaan}

Secara umum, umat Islam di Indonesia lebih patuh dan mengikuti anjuran yang bersumber dari otoritas keagamaan tradisional. Meskipun demikian, terdapat pergeseran yang signifikan pasca gelombang masifnya penggunaan media sosial yang berdampak terhadap proses pencarian sumber pengetahuan yang lebih baru dan sesuai dengan preferensi umat muslim.

\footnotetext{
3 Tren Hijrah Anak Muda: Menjadi Muslim Saja Tidak Cukup - Tirto.ID
} 
Kemunculan internet telah membuka ruang diskusi, proses pencarian pengetahuan, pemulihan krisis identitas, pengalaman spiritual dan distribusi nilai-nilai keagamaan tidak hanya bertumpu pada otoritas tertentu saja. Menurut Eickelman dan Anderson, perkembangan pendidikan massal dan internet melalui produknya, yaitu media baru (media sosial), memunculkan kondisi kesetaraan dalam hal wacana di ruang publik, salah satunya adalah wacana keagamaan (Eickelman \& Anderson, 2003). Konsekuensinya adalah fenomena kemunculan para ustad baru yang dikenal luas melalui jaringan media sosial baik di Instagram, Youtube, Facebook, Podcasts, Telegram maupun WhatsApp.

Terdapat perdebatan di antara para intelektual dan ulama tradisional ihwal komodifikasi Islam di Indonesia. Mereka mengeluhkan bahwa banyak dari penceramah terkenal tidak mendapat pendidikan Islam yang baik.Selain itu, para selebriti dengan pengetahuan Islam yang minim tampil begitu terkemuka sering terbata-bata dan tidak fasih dalam pengucapan istilah-istilah atau dalil-dalil agama (Fealy \& White, 2008). Para pendakwah baru ini merupakan makhluk bentukan mutahir. Selama berabad-abad sebelumnya, para pendakwah dan ulama mencapai kewenangan dan wibawa mereka dengan mengabdikan diri bertahun-tahun mengaji secara mendalam (Heryanto, 2014).

Ariel Heryanto menambahkan, pola-pola perilaku Islami telah berubah secara dramatis pada empat puluh tahun terakhir. Islam saat ini memiliki kehadiran yang lebih kuat dalam kehidupan sosial, budaya, dan politik dibanding pada tahun 1960-an. Jumlah masjid dan jemaahnya telah meningkat tajam sebagaimana popularitas pakaian
Islami dan penggunaan simbol-simbol, serta ekspresi bahasa Islam di media dan tempat-tempat umum. Penerbitan, pendidikan, dan wisata Islam maju dengan pesat. Para pengusaha Muslim pun telah menemukan cara-cara inovatif menggunakan teknologi baru guna mempopulerkan pesan-pesan keagamaan mereka. Islam telah masuk ke kehidupan orang-orang lebih dalam dari sebelumnya dan kaum Muslim mengungkapkan keimanan mereka dalam bermacam jalan.

Organisasi Nahdlatul Ulama (NU) dan Muhammadiyah menampilkan wajah Islam Indonesia yang damai dan bersahabat. Martin Van Bruinessen dalam karyanya 'Post Soeharto Muslim Engagements With Civil Society and Democracy', menyatakan bahwa NU dan Muhammadiyah merupakan pilar masyarakat sipil. Sementara itu, Robert W Hefner (2000) juga menulis tentang Civil Islam: Muslims and Democratization in Indonesia. Sesuai hasil survei dan studi yang mendalam tentang NU dan Muhammadiyah tersebut, maka media massa kemudian menjadikan keduanya sebagai representasi dari komunitas Muslim ketika berbicara tentang hubungan agama dengan negara demokrasi dan sebagainya. Bukan sebaliknya (Sila, 2009).

Sebagai representasi otoritas keagamaan yang telah diterima secara luas, NU dan Muhammadiyah secara tidak langsung menjadi pedoman dalam melakukan distribusi nilai-nilai keislaman di masyarakat. Penelitian ini tidak memfokuskan pada kedua ormas tersebut, melainkan berusaha memahami pandangan dua kelompok hijrah ('Terang Jakarta' dan 'Shift Bandung') terhadap eksistensi otoritas keagamaan terutama dalam dimensi peran dan relasinya satu sama lain. 
Oleh karena itu, basis utama riset ini adalah ekplorasi konsep hijrah dan eksplanasi bergesernya otoritas keagamaan tradisional melalui kemunculan komunitas hijrah. Sehingga, dalam analisisnya keberadaan NU dan Muhammadiyah hanya menjadi panduan untuk memahami arah transformasi nilainilai yang diusung oleh gerakan hijrah.

\subsection{Gerakan hijrah}

Mayoritas individu yang berhijrah diisi oleh kelompok milenial yang sebelumnya telah lekat sebagai pengguna aktif internet. Selain itu, geografis mereka berada di wilayah kota-kota besar yang mulai disesaki oleh simbol dan produk modernisiasi. Kombinasi dua faktor tersebut secara tidak langsung memunculkan situasi pencarian identitas untuk mengisi kegersangan spiritual. Bagi Greg Fealy, wilayah kota itu menggairahkan bagi kelas-kelas menengah karena meluaskan dan memperkaya. Namun juga tidak stabil karena mengancam dan mengasingkan (Fealy \& White, 2008).

Meskipun terdapat perbedaan konteks terhadap pemaknaan terminologi hijrah, esensi dan semangat yang diusung masih tetap sama yakni memahami Islam lebih dekat dan mendalam. Daod Casewit dalam artikelnya 'Hijra As Hisory and Metaphor: $A$ Survey Of Qur'anic and Hadith Sources' membagi pemaknaan hijrah dalam dua jenis berdasarkan rujukan Al-Qur'an dan Hadits: yaitu hijrah sebagai persitiwa historis dan hijrah sebagai metafora (Casewit, 1998).

\footnotetext{
${ }^{4}$ https://tirto.id/ketika-hijrah-bukan-sekadarperbaikan-diri-tapi-juga-aksi-kolektif-fZPP diakses pada 29 Agustus 2020
}

\section{2. 'Terang Jakarta' dan 'Shift Bandung'.}

Gelombang hijrah didominasi oleh kelompok anak muda dengan latar belakang sebagai kelas menengah yang tumbuh di wilayah perkoaan. Seperti di Jakarta, Bandung, Yogyakarta, Malang, Surabaya, dan Makassar. Kota-kota ini adalah representasi wilayah berkembangnya hijrah para kawula muda.

Azhar Irfansyah merunut definisi hijrah sebagai peristiwa historis yang dijelasan dalam Al-Quran lekat dengan kolektivitas umat. Hijrah historis tidak diserukan bukan pada kaum muslim sebagai individu yang terpisah-pisah, melainkan sebagai kolektif umat yang solid. Sedangkan kampanye hijrah yang kini diusung oleh para kelompok gerakan hijrah di Indonesia lebih lekat pada metafor niat amal baik, "perjalanan" dengan orientasi moral dan spiritual. Menurutnya, penggunaan hijrah metafor menyebabkan makna hijrah menjauh dari asal-muasal historisnya yang penuh keagungan. Ia pun memberikan kritik, bahwa tren hijrah metafor sebagai pertaubatan individual membawa gelombang depolitisasi yang memang semakin meluas di bawah hegemoni neoliberalis. ${ }^{4}$ Salah satu indikatornya adalah bergesernya isu-isu di masyarakat yang sebenarnya masuk dalam tantangan kolektif kemudian diubah menjadi tentang individual saja (Etherington \& Jones, 2018).

Fenomena hijrah yang terjadi di Indonesia harus dapat dilihat secara proporsional dengan berbasis pada halhal yang bersifat historis, ideologis, metafora dan kultural. Sebab, tren 
keagamaan menjadi produk entertainment telah terjadi sejak tahun 1990-an di beberapa negara Barat. Sebuah budaya populer yang menjadikan agama sebagai sebuah tren publik sejatinya bukan lagi suatu kasus yang baru terjadi (Einstein, 2007).

\subsection{Model Dakwah}

Metode dakwah konvensionaldi atas mimbar-masih menjadi pilihan yang favorit untuk menyampaikan pesanpesan kebaikan dan intisari pelajaran Islam. Skalanya bisa dijumpai dalam ukuran yang kecil, misalnya di pengajian rumah, dan ukuran besar, seperti jamak dihelat di masjid, lapangan olahraga, ataupun ruangan berkapasitas besar. Para kelompok hijrah sangat pandai memanfaatkan teknologi dengan melakukan inovasi dakwah. Situasi serupa pernah terjadi di Mesir pada tahun 1990-an. Bayat mencatat, mereka pertama kali hanya melakukan dakwah di acara-acara pribadi, baik di rumah-rumah atau perkumpulan-perkumpulan. Namun, sesudahnya memasuki tempattempat publik yang luas dan di pertukaran abad: di televisi (Julia Day Howell dalam Fealy \& White, 2008)

Akan tetapi, sejak kemunculan internet dengan produk new media pada satu dekade terakhir telah menyebabkan terjadinya pergeseran ruang berdakwah. Ansori (2019) menyebutkan bahwa secara terminologi dakwah tidak hanya dilakukan dengan ceramah di atas mimbar. Akan tetapi dakwah juga bisa dilakukan melalui aksi nyata yang lebih dikenal dengan pemberdayaan masyarakat yang mengimplementasikan nilai-nilai dakwah Islam guna mewujudkan masyarakat yang Islami dan sejahtera. Seringkas yang saya perhatikan, komunitas 'Terang Jakarta' dan 'Shift Bandung' memiliki program khusus di bidang pembinaan dan pemberdayaan masyarakat. Hal ini berkaitan langsung dengan misi dakwah mereka.

Meskipun demikian, dakwah melalui jejaring internet bukanlah sebuah hal yang baru. Pada tahun 2000, Fealy mencatat Abdullah Gymnastiar (Aa Gym) yang menjadi mega bintang pendakwah televisi di Indonesia pertama meroket menuju popularitas. Popularitas Aa Gym selanjutnya diikuti oleh penceramah lain seperti ustaz Arifin Ilham, Jeffry Al Buchory, dan Yusuf Mansyur, yang secara masif memanfaatkan perkembangan teknologi informasi.

Pada kemunculan media baru (misalnya whatsapp, Instagram, Youtube, Facebook, Podcasts dan Twitter), penggunaannya lebih didominasi oleh kelompok milenial atau kaum muda yang lebih melek dengan internet serta mengonsumsi informasi dalam intensitas yang tinggi dan belajar otodidak agama secara instan. Di Indonesia kini, 55 persen dari pengguna internet berusia antara 15-19 tahun, dan 70 persen dari mereka menggunakan Facebook (Tempo 2012), menjadikan Indonesia sebagai pusat jejaring sosial kedua terbesar di dunia. Masalah-masalah keagamaan mendominasi segala bentuk media sosial di Indonesia saat ini (Heryanto, 2014).

\subsection{Menuju Media Sosial}

Akhirnya, metode dakwah ikut bergeser ke ranah media baru dengan menyelipkan pesan-pesan pertaubatan individual. Konsep ini selanjutnya dikenal luas sebagai hijrah yang mendapatkan respon positif dari kelompok anak-anak muda urban nan kosmopolit. Ceritacerita pertobatan para penceramah ini penting sebagai daya tarik. Pengalaman spiritual yang hebat dan berdaya 
mengubah cara pandang audience yang sedang dalam proses hijrah. Julia Day Howell mencatat, cerita-cerita yang beredar luas ini memberi dasar bagi para penceramah untuk dipercayai sebagai pemegang otoritas keagamaan walaupun kualifikasi formal keagamaan mereka kurang (Fealy \& White, 2008).

Ulrich Bech menjelaskan, secara sosiologis kosmpolitan memberikan sebuah gagasan tentang proses untuk mengikat sejarah dengan pengalaman (individual dan kolektif) adalah dengan mengintegrasikan nilai-nilainya ke dalam ritus sosial secara simbolik. Agar kosmopolitanisme tersebar luas di antara penduduk (dunia) dan menjadi basis mobilisasi politik, perlu diwujudkan dalam simbol dan ritual agar dapat menjadi dasar identitas pribadi. Poin terakhir ini penting karena ini pada akhirnya menjadi fondasi politik terakhir dari kosmopolitanisme; perasaan individu bahwa mereka melakukan sesuatu yang salah dengan mengabaikan penderitaan. Jika dimobilisasi dengan baik, situasi ini akan menciptakan aksi politik kosmopolitan. ${ }^{5}$

Komunitas Terang Jakarta dan Pemuda Hijrah (Shift Bandung) adalah dua gerakan hijrah yang sangat populer di kalangan anak-anak muda urban. Kedua komunitas ini sama-sama berupaya melakukan proses kaderisasi atau menjaring anggota melalui penggunaan media sosial. Ketokohan pendiri setiap komunitas menjadi nilai surplus untuk menggaet calon anggota baru. Selain itu, para selebritas yang telah ikut berhijrah dijadikan 'magnet' untuk mempertegas kampanye dan strategi hijrah yang dilakukan oleh komunitas.

Terang Jakarta, misalnya, cenderung mengambil preferensi promosi lewat public figure seorang selebritas daripada ketokohan setiap anggotanya. Hal ini didasari nilai popularitas sang selebritas yang lebih tinggi dan telah memiliki basis fans yang organik selama perjalanan karirnya. Dalam prosesnya, tren hijrah para selebritas juga membentuk komunitas baru yang terkesan lebih eksklusif. Pratt menyebutkan bahwa paradigma dari eksklusif terbagi ke dalam tiga tipe, pertama terbuka, kedua tertutup, dan terakhir kelompok eksklusif yang ekstrem (Pratt, 2007). Namun demikian, pola kampanye dan seruan yang dilakukan tetap sama, melalui media sosial. Untuk menunjukkan keseharian mereka yang baru, para selebritas menggunakan cyberspace untuk terus berkomunikasi dengan penggemar (Anisa, 2018).

Shift Bandung menerapkan strategi yang berbeda daripada Terang Jakarta. Meskipun keduanya lahir dan berkembang di kota besar yang dihiasi gemerlap dunia hiburan, Shift lebih menekankan pada figur ketokohan pribadi yang berasal dari komunitas asalnya. Sehingga, tidak mengherankan jika komunikasi persuasif Shift lebih banyak mengandalkan basis fans atau penggemar.

Selebritas ataupun figur yang dianggap merepresentasikan popularitas dengan kesalehan pribadi secara tidak langsung mendapatkan pengakuan dari publik. Hal ini dapat dilacak, misalnya, 
pemberian gelar ustaz/ustazah kepada mereka. Qasim Zaman (2009) dalam Islam ad Modernity mengistilahkan fenomena ini dengan "storytellers and popular preachers", yang mana pada kemunculan artis hijrah sebagai pendakwah mampu menggeser fondasi otoritas keagamaan yang sebelumnya selalu merujuk kepada ulama (Masud et al., 2009).

Konsekuensi logis yang biasa dijumpai ketika pergeseran otoritas keagamaan adalah semakin mudah diterimanya pesan-pesan, nasehat, yang disampaikan oleh mereka melalui mimbar ceramah konvensional ataupun audio-visual (internet-media baruyoutube, instagram). Di Terang Jakarta, terma yang digunakan untuk selebritas adalah influencer dan micro influencer. Sedangkan di Shift menggunakn istilah ketokohan individual. Lewis menjelaskan micro-celebrities tidak hanya sebagai stylemediator, tetapi juga spiritual advisor. Dengan menarik pengikut di media sosial Instagram, para micro-celebrities Muslim, dapat berpotensi membentuk "Publik Islam" mereka sendiri (Fadil, 2015). Menurut Noorhaidi dan Zachary, publik Islam adalah sekelompok warga yang dapat menunjukkan praktik agama dalam ruang publik (Hasan, 2009 dan Abuza, 2006). Praktik agama tidak hanya dalam ritual namun juga ekspresi politik, transaksi resmi, aktivitas ekonomi, praktik sosial dan budaya dalam kehidupan sehari-hari. Publik Islam ini juga akan cenderung bersikap positif terhadap implementasi atas hukum Islam atau biasa disebut syariah Islam (Anisa, 2018)

\subsection{Jamaah Dan Figur Sentral}

Dakwah yang dilakukan oleh 'Terang Jakarta' dan 'Shift Bandung' lebih dominan dilakukan melalui media sosial.
Hal ini sangat beralasan, karena mereka memiliki basis jamaah dari kelompok anak-anak muda yang lebih melek dengan internet.

Table 1. Perbandingan antara 'Terang Jakarta' dengan 'Shift Bandung' di Media Sosial

\begin{tabular}{|c|l|l|l|}
\hline No & \multicolumn{1}{|c|}{$\begin{array}{c}\text { Media } \\
\text { Sosial }\end{array}$} & $\begin{array}{l}\text { Terang } \\
\text { Jakarta }\end{array}$ & $\begin{array}{c}\text { Shift } \\
\text { Bandun } \\
\text { g }\end{array}$ \\
\hline $\mathbf{1}$ & Motto & $\begin{array}{l}\text { 'generasi } \\
\text { yang } \\
\text { ingin } \\
\text { menjadi } \\
\text { lebih } \\
\text { baik' } \\
\text { maen, } \\
\text { banyak } \\
\text { manfaat' }\end{array}$ \\
\hline $\mathbf{2}$ & Instagram & 62 Ribu & 1.9 Juta \\
\hline $\mathbf{3}$ & Youtube & 3.89 Ribu & $\begin{array}{l}\text { 462 } \\
\text { Ribu }\end{array}$ \\
\hline $\mathbf{4}$ & Facebook & 148 & $\begin{array}{l}141 \\
\text { Ribu }\end{array}$ \\
\hline $\mathbf{5}$ & Twitter & - & $\begin{array}{l}57.5 \\
\text { Ribu }\end{array}$ \\
\hline & & & \\
\hline
\end{tabular}

Figur penting di 'Terang Jakarta' adalah Dimas Wibisono sebagai inisiator dan ustad Abi Makki sebagai pembinanya. Sedangkan di 'Shift Bandung' figur sentral sekaligus daya tarik para jamaah adalah sosok Ustad Hanan Attaki. Secara tidak langsung, kedua komunitas ini menjalin hubungan yang cukup dekat sebagai sesama komunitas hijrah yang mengusung dakwah Islam di era digital.

Table 2. Figur-figur di 'Terang Jakarta' dan 'Shuft Bandung'

\begin{tabular}{|c|l|l|}
\hline No & Komunitas & \multicolumn{1}{|c|}{ Figur } \\
\hline 1 & $\begin{array}{l}\text { Terang } \\
\text { Jakarta }\end{array}$ & Ustad Abi Makki \\
\hline 2 & $\begin{array}{l}\text { Shift } \\
\text { Bandung }\end{array}$ & $\begin{array}{l}\text { Ustad Hanan } \\
\text { Attaki }\end{array}$ \\
\hline
\end{tabular}

\subsection{Wajah Islam yang Baru}

Hijrahnya anak-anak muda dan selebritas memberikan dampak yang luar 
biasa terhadap pembentukan image Islam yang baru. Proses persuasif dan kampanye tentang belajar Islam itu sesuatu yang asyik, keren, dan santai adalah beberapa kata kunci yang mudah ditemui. Para individu yang terlibat di dalamnya juga merasa memiliki satu pemahaman yang sama tentang pengalaman spiritual mencari identitas, jati diri, dan enggan untuk mengikuti acara pengajian secara langsung.

$$
\text { Dakwah yang dilakukan }
$$
menggunakan bahasa dan diksi yang ringan agar mudah dipahami. Pesanpesan yang disampaikan oleh para artis ataupun mereka yang hijrah terasa lebih fresh karena sesuai dengan realitas sosial (Echchaibi, 2011). Najib Kailani, mengamati fenomena dakwah Islami dikemas secara populer tersebut sebagai "Islam yang ready to use". ${ }^{6}$

Dakwah yang kreatif dan berusaha keluar dari narasi besar pengajian formal seperti di masjid dan musholla menjadi faktor penarik bagi anak-anak muda untuk berhijrah. Media sosial, ruang publik seperti mall, dan kafe adalah arena yang dijadikan sebagai alternatif untuk berdakwah. Sebab, target yang ingin digaet adalah anak-anak muda yang berlatar kelas menengah urban namun masih ingin merayakan kesenangan dunia dengan batasan-batasan tertentu sesuai koridor Islam. Menurut Ariel Heryanto, sebagaimana sejawat mereka yang sekuler dan non-Muslim, generasi baru dan terdidik Muslim di seluruh dunia berharap memiliki kemerdekaan dan uang yang memungkinkan mereka untuk menikmati selera kebudayaan mereka sambil memelihara kehormatan diri tanpa mengorbankan keimanan mereka (Heryanto, 2014).

Di Indonesia, status baru orang muda Muslim telah memunculkan kebutuhan baru di ruang-ruang politik, kebudayaan, dan juga agama (Heryanto, 2014). Untuk mengafirmasi proses dakwah berlangsung secara berkelanjutan, diperlukan figure atau tokoh sebagai sentral pengetahuan. Oleh karena itu, para ustaz muda yang enerjik dan gaul menjadi aktor utama untuk merealisasikan hal tersebut. Ariel Heryanto mencatat, generasi pendakwah baru yang merupakan figur-figur religius mentereng tidak dihasilkan oleh pendidikan keagamaan formal yang berlangsung selama bertahun-tahun. Kebanyakan dari mereka sama sekali tak berlatar belakang pendidikan agama (Heryanto, 2014). Konsep ini barangkali tidak berlaku di Shift Bandung, ustaz Hanan Attaki memiliki latar pendidikan agama di Al Azhar, Mesir. Meskipun demikian, penjelasan Ariel Heryanto dapat merepresentasikan geliat hijrah yang ada di komunitas Terang Jakarta ataupun beberapa gerakan hijrah lain (khususnya kelompok selebritas) yang tidak menimba ilmu agama Islam secara organik di pesantren. Bagi para pendengar atau pengikut mereka, para pendakwah baru ini memiliki penampilan bak bintang music rock. Mereka memperlihatkan tren terbaru dan terkeren dalam pidato, pakaian, dan potongan rambut (Heryanto, 2014). Mereka memuaskan kebutuhan generasi baru, terutama orang-orang kaya 'yang telah belajar mengambil jalan pintas dalam mencari ilmu, atau belajar untuk menjadi murid yang patuh' ("Asef Bayat

${ }^{6}$ https:/ / tirto.id/tren-hijrah-anak-muda-menjadimuslim-saja-tidak-cukup-ds9k diakses pada 1 September 2020 
in Newsletter 10 Muslim Responses to Globalization," 2002). Ringkasnya, otoritas keagamaan baru di Indonesia tidak lagi dibangun atas dasar sebagaimana otoritas keagamaan tradisional, melainkan kemampuan para tokoh tersebut menggabungkan nilainilai keislaman dengan nilai-nilai sekuler (Watson, 2005; Hoesterey, 2008; Rudnyckyj, 2009; Howell, 2013; Hasan, 2012; Kailani, 2019).

Kesan paling kuat dan melekat kepada individu yang berhijrah adalah predikat saleh. Makna kesalehan di sini bersifat pribadi, yakni perbaikan diri melalui ritual ibadah yang bersifat vertikal sebagai perwujudan relasi dengan Tuhan Yang Maha Esa. Bagi Komunitas Shift Bandung, upaya mengarahkan hijrah sebagai sebuah pride (kebanggaan) untuk setiap individu dapat dikatakan sukses. Indikatornya adalah banyaknya anggota baru yang tidak canggung lagi untuk datang menghadiri taklim di Masjid AlLathiif dengan busana khas anak muda yang gaul. Selain itu, Shift juga berusaha mengikis stigma atau citra bahwa belajar Islam dapat dilaksanakan dengan santai. Hal ini seturut motto mereka, 'Banyak Main, Banyak Manfaat'. Seruan tersebut dipertegas dengan pernyataan lain, "ayo kita bareng-bareng belajar sambil bermain, semakin kita belajar maka kita bakal makin luwes dalam bergaul".

Sementara itu, komunitas Terang Jakarta juga melakukan hal yang serupa. Dengan fokus mengambil peran sebagai 'jembatan' bagi individu yang hendak belajar Islam, kemasan dakwahnya pun sama yakni memanfaatkan ruang publik sebagai upaya membangun citra Islam yang ramah, keren, dan asyik. Dengan demikian, menjadi orang alim sekarang ini dapat dikonstruksi sekaligus pula diakui oleh orang lain di sekelilingnya (Wasisto, 2015). Relasi antara ritual kesalehan sosial dengan kemunculan kelas menengah Muslim dapat dianalisis dalam dua tujuan penting. Faktor pertama, pengolahan nilai-nilai kebajikan Islam sebagai bentuk identitas pribadi dan faktor kedua, terbentuknya ummah sebagai bentuk eskpresi kebebasan dan keadilan yang selaras dengan pembangunan kultur dan kebudayaan (Harmsen: 2008: 318 dalam Wasisto, 2015).

Harus diakui, tren hijrah semakin digemari karena pola pengemasannya yang menarik dan sangat lentur dengan kultur anak-anak muda. Ada korelasi cukup kuat di antara peningkatan kesalehan keagamaan yang terlihat jelas dan luas di kalangan kaum Muslimin Indonesia sejak akhir dasawarsa 1980an. Indikasinya nampak secara kasat mata, mulai dari kebangkitan kelas menengah Muslim, makin meluasnya pemakaian jilbab, kian meningkatnya jumlah jamaah haji dan umrah, makin semaraknya berbagai produk 'syari'ah' atau 'halal', dan terus menguatnya filantropi Islam (Azra, 2018). Situasi ini memiliki kemiripan dengan meningkatnya gairah mempelajari Islam yang terjadi di Mesir pada tahun 1990-an. Asef Bayat menjelaskan fakta sosial tersebut sebagai bentuk kesalehan aktif. Menurutnya, kelompok-kelompok muslim tersebut memiliki agenda yang bersifat pribadi, apolitis, terarah pada keselamatan pribadi, penguatan etika, dan aktualisasi diri (Bayat, 2007). Julia Day Howell, dalam artikelnya 'Variasi-variasi Kesalehan Aktif: Profesor dan Pendakwah Televisi Sebagai Penganjur Sufisme' menjelaskan, jika telah tiba masanya, mereka akan memberi tanggapan dan membaktikan diri lagi pada Islam yang sejati dengan membagi cerita-cerita mereka kepada orang lain. Sifat aktif dari kesalehan ini terlihat pada titik balik ketika seseorang secara sadar memutuskan hubungan dengan masa 
lalunya yang kelam, juga adanya kewajiban untuk menceramahi orang lain yang masih beriman secara pasif (Fealy \& White, 2008). Ritual begitu menonjol dalam praktik kesalehan aktif ini, khususnya melaksanakan salat lima waktu, tetapi juga dalam acara-acara di televisi yang dihadiri banyak orang. Para penceramah bergaya baru ini tipis perbedaan pendapatnya dan tebal ritualnya (Bayat, 2007).

\section{Kesimpulan}

Pergeseran otoritas keagamaan dipengaruhi oleh munculnya media sosial melalui gerakan hijrah. Komunitas hijrah secara masif melakukan persuasif dakwah yang santai dengan program-program yang sesuai dengan psikologis dan kebutuhan anak-anak muda. Materialisme dan kemodisan konsumsi Islam tidak sepenuhnya bisa dipandang tidak berarti atau tidak penting. Banyak Muslim kelas menengah yang hanya punya sedikit waktu dan ketertarikan untuk mengikuti wacana ilmiah. Namun, mereka serius dalam hal meningkatkan pemahaman keagamaan mereka dan mempraktikkan keimanan mereka melalui ibadah-ibadah. Keinginankeinginan yang saleh dari Muslim juga telah memberi momentum pada kampanye-kampanye untuk standar etika publik yang lebih tinggi dan reformasi politik (Fealy \& White, 2008).

Kemunculan kelompok yang dianggap menghadirkan otoritas keagamaan baru perlu dilihat sebagai fakta baru atas eksistensi otoritas tradisional yang selama ini telah mendapatkan pengakuan. Van Bruinessen mendefinisikan Islam konservatif sebagai "berbagai aliran pemikiran yang menolak penafsiran ulang atas ajaran-ajaran Islam secara liberal dan progresif, dan cenderung untuk mempertahankan tafsir dan sistem sosial yang baku” (Van Bruinessen, 2013).

Gerakan transnasional, menurut Van Bruinessen, dalam kadar tertentu, mengurangi otoritas keagamaan ormasormas Islam di Indonesia, seperti Nahdlatul Ulama (NU), Muhammadiyah, Persatuan Islam (Persis), dan Majelis Ulama Indonesia (MUI). Sebagai contoh, para pegiat dakwah Salafi tidak pernah merujuk kepada fatwa yang diberikan oleh ormas-ormas Islam tersebut di atas untuk masalah-masalah keagamaan yang terjadi di Indonesia. Sebagai gantinya, mereka meminta fatwa langsung kepada guru-guru mereka di Timur Tengah. Hal ini menunjukkan bahwa para aktivis Salafi tidak mempercayai wewenang keagamaan ormas Islam di Indonesia (Wahid, 2014).

Pusaran kemajuan teknologi informasi secara tidak langsung memunculkan kelompok Islam yang baru dengan dakwah melalui media sosial. Untuk mengantisipasi munculnya kelompok ekstrimisme dan menguatnya konservatisme di ruang publik, diperlukan gerakan alternatif. Dalam buku Progressive Islam as Alternative Voices dijelaskan tentang konsep Progresif Islam. Merujuk Wahyudi (Akmaliah, 2020), Syed Farid Alatas (2020, 89-117) mendefinisikan apa yang disebut dengan Progresif Islam. Alih-alih sekadar menjelaskan posisinya sebagai seorang Muslim yang mengadvokasi agamanya sendiri dengan merujuk Omid Safi, Progresif Islam adalah orang yang melakukan advokasi kepada setiap orang dengan tidak melihat latar belakang keagamaan, etnis, sosial, ataupun poltiknya. Lebih lanjut, Wahyudi menjelaskan bahwa fokus advokasi di sini adalah kepada kelompok subaltern dari pelbagai bentuk, baik itu kemisinan, ketertindasan, ataupun bentuk-bentuk 
marginalisasi lainnya. Tugas suara alternatif ini adalah berupaya untuk menyuarakan mereka yang tidak bersuara, memberikan kekuatan kepada mereka yang tidak memiliki kekuatan, sekaligus juga melakukan konfrontasi kepada kelompok yang melakukan degradasi martabat kemanusiaan kepada kelompok mustad'afun. Tidak hanya berdasarkan dari Al-Quran dan Sunnah, Progresif Islam adalah mereka yang juga memiliki orientasi dengan modernitas sambil menjaga tradisi dan tidak hanya bersandarkan kepada satu pemikiran Islam. Dengan kata lain, suara-suara ini adalah sebagai upaya yang mengimbangi eksrtremisme yang terjadi, baik di ruang privat maupun ruang publik.

Syed Farid Alatas (2020, 98-110) menawarkan 10 butir sikap yang bisa dilakukan dan dipegang oleh kelompok Progressif Islam, antara lain; 1) keseimbangan antara pengetahuan dan praktik (ilm'amal); 2) terinspirasi dari kritik Orientalisme Edward Said; 3) adanya ruang kritik, baik internal maupun eksternal; 4) bersikap inklusif sekaligus eksklusif di sisi lain, dimana harus menerima keragaman dan pluralitas tapi harus secara eksklusif bisa mempertahanan tradisi yang dimilikinya; 5) adanya keberlanjutan antara menjaga tradisi dan merengkuh modernitas secara bersamaan; 6) adanya keterkaitan antara aspek ekstorik dan esotorik, dengan menautkan antara hukum-hukum Islam yang dijelaskan oleh para Ulama sekaligus ketersambungan dengan masyarakat luas dengan memperhatikan etika, moralitas, dan pengalaman keagamaan; 7) mempercayai rasionalitas dan nonrasionalitas dengan memadukan antara pengetahuan agaa yang bisa diterima akal sekaligus juga aspek pengalaman keagamaan, seperti yang dilakukan oleh para sufi; 8) kebebasan sekaligus pembatasan, dengan memperhatikan aturan negara yang melakukan regulasi kepada kelompok-kelompok keras kepala sekaligus juga memberikan ruang kepada kebebasan berpikir dan akademik; 9) mengkritik struktur global kapitalisme yang menindas dengan menempatan diri bukan menjadi bagian dari struktur tersebut; 10) menyeimbangkan antara kehidupan dunia dan akhirat (Akmaliah, 2020).

Oleh karena itu, otoritas keagamaan baru yang muncul melalui komunitas hijrah pada prinsipnya memiliki potensi untuk menjadi kelompok Progressif Islam. Sebab, proses pendekatan, kaderisasi, dan program yang dijalankan dapat disesuaikan dengan nilai-nilai moderasi beragama yang ada di Indonesia.

Riset ini menemukan bahwa media sosial memiliki peran penting dalam proses kampanye, rekrutmen, dan dakwah yang dilakukan oleh komunitas hijrah. Polanya, di 'Terang Jakarta' cenderung pada preferensi penggunaan public figure sebagai daya pikat dalam proses kaderisasi. Tentu saja, selebritas yang telah berhijrah telah menyandang gelar ustad dari para jamaahnya yang selanjutnya diafirmasi oleh media dalam proses sosialisasinya.

Sementara itu, komunitas 'Shift Bandung' lebih fokus pada penguatan ketokohan lokal yang merupakan figurfigur sentral baik dalam bidang kesenian, olahraga maupun keagamaan. Tidak heran, jika Ustad Hanan Attaki semakin sohor dan popularitasnya semakin menjulang karena mendapatkan dukungan yang sangat masif dari para jamaahnya baik yang ada di media sosial maupun dalam rutinitas sosial. Penggunaan budaya populer adalah strategi kunci yang dilakukan oleh Pemuda Hijrah Shift Bandung. Sebagai 
tambahan, jaringan kelompok hijrah dan dakwah mereka terbentuk secara organik dan terus meluas di beberapa wilayah Bandung Utara, Barat, Selatan dan Timur.

Pada prinsipnya, kedua komunitas ini cukup inklusif dan memiliki misi dakwah yang sama seperti organisasi Islam lainnya, misalnya Nahdlatul Ulama (NU) dan Muhammadiyah. Namun, dalam proses pembelajaran dan penggalian keilmuan Islam, mereka lebih menyukai kedekatan emosional dan psikologis dengan ustad-ustad melalui jaringan pertemanan saja. Meskipun demikian, baik 'Terang Jakarta' maupun 'Shift Bandung' merasa sangat senang jika dilakukan sinergitas hubungan dengan otoritas keagamaan, seperti NU dan Muhammadiyah khususnya pada program-program dakwah dan terkait kepentingan umat.

Komunitas hijrah terbukti mampu mengemas dakwah pada ranah media sosial dengan daya persuasif yang lebih baik daripada otoritas keagamaan tradisional. Seturut hal tersebut, Fealy menyatakan bahwa dinamika pasar mendikte bahwa agama mestilah semakin dibawa ke dalam budaya populer, khususnya melalui media elektronik. Ia mesti ditampilkan dalam bentuk yang menghibur dan mudah dicerna. Jadi, tidaklah mengejutkan bila kita menemukan para penceramah menggunakan perangkat-perangkat dramatik seperti pencahayaan yang memengaruhi pikiran, musik, tata panggung, dan teknik-teknik presentai dari yang jenaka hingga yang menggerakkan emosi dan meningkatkan moral (Fealy \& White, 2008).

Secara tidak langsung, temuan riset ini mengafirmasi telaah Muhammad Adlin Sila yang memaparkan bahwa konsep institusi sosial dalam bentuk paham keagamaan atau organisasi keagamaan membagi komunitas umat Islam ke dalam dua kelompok mainstream, pertama adalah kelompok dominan yang terdiri dari NU dan Muhammadiyah. Sedangkan kelompok tidak dominan atau minoritas yang mengambil kasus FPI, MMI dan sejenisnya. Adlin Sila menegaskan terdapat kecenderungan bahwa makin tidak dominan atau kecil suatu komunitas muslim, dan makin baru komunitas muslim terbentuk, semakin mengalami masalah dalam mengembangkan budaya kewargaan. Penyebab timbulnya kesenjangan seperti itu adalah karena selain pendekatan dan pemahaman yang berbeda terhadap teks dan konteks, juga karena lemahnya jaringan sosial yang lintas afilliasi (cross-cutting affiliation) antara kelompok dominan dan tidak dominan, sehingga berimplikasi pada tersendatnya transmisi budaya kewargaan (Sila, 2009).

Oleh karena itu, perlu adanya sosialisasi dan interaksi yang mendalam terkait relasi otoritas keagamaan tradisional dengan otoritas keagamaan baru agar tercipta sinergitas dalam proses dakwah dan distribusi nilai-nilai Islam yang utuh dan komprehensif.

Riset ini menemukan bahwa komunitas hijrah pada prinsipnya tetap mengakui keberadaan otoritas keagamaan yang sudah ada, seperti NU dan Muhammadiyah terutama perannya dalam dakwah Islam di Indonesia. Secara umum, tidak ada tafsir dan persepsi yang berbeda oleh komunitas hijrah terhadap pemahaman nilai-nilai keislaman. Namun, titik pertemuan yang perlu menjadi perhatian adalah upaya membangun pola komunikasi dan koordinasi yang kooperatif antara otoritas keagamaan tradisional dengan komunitas hijrah. Hal ini penting 
dilakukan agar tercipta nuansa moderasi beragama yang inklusif, utuh, dan komprehensif khususnya dalam memahami wacana keislaman Indonesia.

\section{References}

Abuza, Z. (2006). Political Islam and violence in Indonesia. In Political Islam and Violence in Indonesia. https://doi.org/10.4324/97802039 69250

Akmaliah, W. (2020). Mengartikulasikan Suara Alternatif Muslim Asia Tenggara. Studia Islamika. https://doi.org/10.36712/sdi.v27i2. 16764

Anisa, F. (2018). Hijrah Milenial: Antara Kesalehan dan Populism. Maarif.

Azra, A. (2018). Kesalehan dan politik: Islam Indonesia. Studia Islamika. https://doi.org/10.15408/sdi.v25i3. 9993

Casewit, D. S. (1998). HIJRA AS HISTORY AND METAPHOR: A SURVEY OF QUR'ANIC AND HAD?TH SOURCES. The Muslim World, 88(2), 105-128. https://doi.org/10.1111/j.14781913.1998.tb03650.x

ECHCHAIBI, N. (2011). From audio tapes to video blogs: the delocalisation of authority in Islam. Nations and Nationalism, 17(1), 2544. https://doi.org/10.1111/j.14698129.2010.00468.x

Eickelman, D. F., \& Anderson, J. W. (2003). Redefining Muslim Publics. New Media in the Muslim World: The Emerging Public Sphere.

Einstein, M. (2007). Brands of Faith. In Brands of Faith: Marketing Religion in a Commercial Age. Routledge. https://doi.org/10.4324/97802039
38874

Etherington, D., \& Jones, M. (2018). Restating the post-political:

Depoliticization, social inequalities, and city-region growth. Environment and Planning A, 50(1), 51-72. https://doi.org/10.1177/0308518X 17738536

Fadil, N. (2015). Modest fashion: styling bodies, mediating faith. Material Religion. https://doi.org/10.1080/17432200. 2015.1059132

Fealy, G., \& White, S. (2008). Expressing Islam: Religious life and politics in Indonesia. In Expressing Islam: Religious Life and Politics in Indonesia.

Hasan, N. (2009). The making of public Islam: Piety, agency, and commodification on the landscape of the Indonesian public sphere. Contemporary Islam. https://doi.org/10.1007/s11562009-0096-9

Hasan, N. (2012). Piety, Politics, and Post-Islamism: Dhikr Akbar in Indonesia. Al-Jami'ab: Journal of Islamic Studies. https://doi.org/10.14421/ajis.2012. 502.369-390

Heryanto, A. (2014). Identity and pleasure: The politics of Indonesian screen culture. In Identity and Pleasure: The Politics of Indonesian Screen Culture.

https://doi.org/10.1355/sj31-1k

Hoesterey, J. B. (2008). Marketing morality: The rise, fall and rebranding of Aa Gym. In Expressing Islam: Religious Life and Politics in Indonesia. 
Howell, J. D. (2013). "Calling” and "training": Role innovation and religious de-differentiation in commercialised Indonesian islam. Journal of Contemporary Religion. https://doi.org/10.1080/13537903. 2013.831650

Kailani, N. (2019). 8. Preachers-cumTrainers: The Promoters of Market Islam in Urban Indonesia. In Islam in Southeast Asia. https://doi.org/10.1355/97898148 18001-010

Masud, M., Salvatore, A., \& van Bruinessen, M. (2009). Islam and modernity: Key issues and debates. In Islam and Modernity: Key Issues and Debates.

$\mathrm{N}$ e w s l e t t e r 10 Muslim Responses to Globalization. (2002). Religion, July.

Pratt, D. (2007). Exclusivism and Exclusivity: A Contemporary Theological Challenge. Pacifica: Australasian Theological Studies, 20(3), 291-306. https://doi.org/10.1177/1030570X 0702000304

Rudnyckyj, D. (2009). Spiritual economies: Islam and neoliberalism in contemporary Indonesia. Cultural Anthropology. https://doi.org/10.1111/j.15481360.2009.00028.x

Sila, M. A. (2009). Menantang Negara Sekuler: Upaya Islamisasi Hukum di Indonesia. Studia Islamika, 16(2). https://doi.org/10.15408/sdi.v16i2. 486

Van Bruinessen, M. (2013). Contemporary developments in Indonesian Islam: Explaining the "conservative turn." In Contemporary
Developments in Indonesian Islam: Explaining the "Conservative Turn." https:/ / doi.org/10.1080/00074918. 2013.850644

W.Creswell, J. (2014). Research Design: Qualitative, Quantitative and Mixed Methods Approaches. In $S A G E$ Publications.

Wahid, D. (2014). Kembalinya Konservatisme Islam Indonesia. Studia Islamika. https://doi.org/10.15408/sdi.v21i2. 1043

Wasisto, J. R. (1970). KESALEHAN SOSIAL SEBAGAI RITUAL KELAS MENENGAH MUSLIM. IBD A : Jurnal Kajian Islam Dan Budaya. https://doi.org/10.24090/ibda.v13i 2.667

Watson, C. W. (2005). A popular Indonesian preacher: The significance of Aa Gymnastiar. In Journal of the Royal Anthropological Institute. https://doi.org/10.1111/j.14679655.2005.00261.x 